\title{
Microbial Kinetic Resolution of Aroma Compounds Using Solid-State Fermentation
}

\author{
Filip Boratyński * (i), Ewa Szczepańska, Aleksandra Grudniewska and Teresa Olejniczak \\ Department of Chemistry, Wroclaw University of Environmental and Life Sciences, Norwida 25, 50-375 Wrocław, \\ Poland; ewa.szczepanska@upwr.edu.pl (E.S.); aleksandra.grudniewska@upwr.edu.pl (A.G.); \\ teresa.olejniczak@upwr.edu.pl (T.O.) \\ * Correspondence: filip.boratynski@upwr.edu.pl; Tel.: +48-71-320-5257
}

Received: 14 December 2017; Accepted: 13 January 2018; Published: 16 January 2018

\begin{abstract}
A novel microbial approach to the production of enantiomerically enriched and pure aroma compounds based on kinetic resolution via solid-state fermentation is proposed. Twenty-five filamentous fungi were screened for lipase activity and enantioselective hydrolysis of a volatile racemic ester (1-phenylethyl acetate (1)) and several racemic lactones (trans and cis whisky lactones $(4,5), \gamma$-decalactone (7), $\delta$-decalactone (8), (cis-3a,4,7,7a-tetrahydro-1(3H)-isobenzofuranone) (9)). Solid-state fermentation was conducted with linseed and rapeseed cakes. Kinetic resolution afforded enantiomerically enriched products with high enantiomeric excesses (ee $=82-99 \%$ ). The results highlight the potential economic value of solid-state fermentation using agroindustrial side-stream feedstocks as an alternative to more expensive processes conducted in submerged fermentation.
\end{abstract}

Keywords: aroma compounds; kinetic resolution; solid-state fermentation; agro-industrial side stream; rapeseed cake; linseed cake; lactones; esters

\section{Introduction}

The food industry generates large quantities of wastes and by-products, and research interest in efficient use of agroindustrial residues has been increasing [1]. Several bioprocesses that use these residues as substrates have been developed, including production of enzymes, single cell proteins, ethanol, organic acids, biopolymers, and secondary metabolites [2]. Solid-state fermentation (SSF) constitutes a microbial culture method alternative to submerged fermentation (SmF). SSF lowers the capital investment that is required for particular bioprocesses by approximately $78 \%$ in comparison to $\mathrm{SmF}$ [3]. Because growth media account for approximately $40 \%$ of the total cost of bioprocessing, it is reasonable to use inexpensive raw materials such, as agricultural by-products [4].

Oilseed cakes are solid residues that are obtained after pressing of oil seeds. They can constitute up to $75 \%$ of total seed weight. Oilseed cakes are rich in carbohydrates, proteins, fat, and cellulose, and therefore provide excellent media for growth of microorganisms [5]. The world market for oilseed cakes is dominated by soybean, rapeseed, cottonseed, groundnut, sunflower, and linseed cakes.

Microbial SSF on renewable agroindustrial side-stream products is ideal for efficient production of industrially important biocatalysts, such as lipases, proteases, cellulases, and amylases [6]. Application of microbial enzymes or whole cells permits transformation with high chemo-, regio-, and enantioselectivity [7]. Notably, biotransformation is an environmentally friendly process because it can be conducted under mild conditions, requires few chemicals, and produces little toxic chemical waste. In the pharmaceutical, agricultural, and fine chemical industries, there is a strong demand for the production of the enantiopure forms of chiral compounds, and biocatalysis is therefore being used to manufacture a wide range of products [8]. 
Increasing attention is being paid to the origins of food additives, and those with natural origins are preferred. Compounds obtained by biotransformation, according to United States and European Union regulations, are regarded as natural [9]. Interest in biotechnological production of natural and natural-identical flavor compounds has recently increased [10]. One group of additives with well-characterized flavor properties are compounds that contain ester bonds, including lactones, which are characterized by an intense, specific aroma, and which are used in the food, cosmetic, and pharmaceutical industries. Their fragrance depends on the size of the ring, the type of substituents, the presence of unsaturated bonds, and the configuration of the chiral centers [11].

One common aroma lactone is whisky lactone. It is essential for the flavoring of aged alcoholic beverages, such as whisky, cognac, brandy, and wine. It is also used as an aroma ingredient of flavored sweets and beverages, as well as a variety of baked foods and tobacco. Four stereoisomers of whisky lactone are known, and their olfactory properties are determined by their spatial structure [12]. $\gamma$-Decalactone was originally isolated from fruits, meat, and dairy products. It enriches food products with an intense scent of peach or coconut. The $S$ enantiomer of $\gamma$-decalactone occurs naturally in mango, while the $R$ enantiomer is found in most fruits, especially in peaches [13]. A reliable process based on the microbial transformation of castor oil secures the production of natural $(+)-(R)-\gamma$-decalactone, whilst the (S)-enantiomer is not easily available yet [14]. $\delta$-Decalactone, with its creamy, sweet, milky, coconut-peach flavor, is of great interest to the food industry. It is a well-known constituent of the aroma of dairy products and some fruits [15]. cis-3a,4,7,7a-Tetrahydro-1(3H)-isobenzofuranone is the precursor of the phthalide-derived lactones that are abundant in fruits in the family Apiaceae, which are characterized by a celery-like aroma [16]. 1-Phenylethyl acetate is a well-known flavoring used in many countries as a food additive. Its aroma has been described as sweet and fruity, woody, and tropical with floral nuances; it is found in a wide range of fruits and vegetables, such as strawberry, melon, avocado, pineapple, and banana. It is a highly valued natural volatile ester that is widely used as an additive in cosmetics, foods, and pharmaceuticals [17].

The aim of this study was microbial kinetic resolution of aroma compounds. Whole cells of filamentous fungi growing on rapeseed (RC) and linseed cakes (LC) were screened for their ability to produce enantiomerically pure lactones and esters. To the best of our knowledge, only a few reports have been published on biotransformation via SSF. Although numerous hydrolases are produced by SSF, only a few reports have discussed their application in biotransformation. Macedo et al. [18] described the production of lipases by SSF and preparation of lyophilized powder of extracted enzymes used for synthesis of short chain citronellyl esters. Only one study, conducted by Nagy et al. [19], has examined lipases produced by SSF as catalysts for kinetic resolution of racemic secondary alcohols. When considering the prevalence of application of these aroma compounds in the food industry, and the economic benefits of sustainable management of agricultural side streams, this approach is undeniably attractive.

\section{Results and Discussion}

The stereoselectivity of hydrolysis catalyzed by enzymes produced by filamentous fungi in solid-state fermentation (SSF) was tested with various aroma compounds: 1-phenylethyl acetate (1), a mixture of trans and cis whisky lactones $(4,5), \gamma$-decalactone (7), $\delta$-decalactone (8), and cis-3a,4,7,7atetrahydro-1(3H)-isobenzofuranone (9) (Scheme 1). SSF was conducted on oilseed cakes from linseeds and rapeseeds, which are by-products of the oleoindustry that contain all essential ingredients for fungal growth, especially the fatty acids that are required for lipase biosynthesis. 


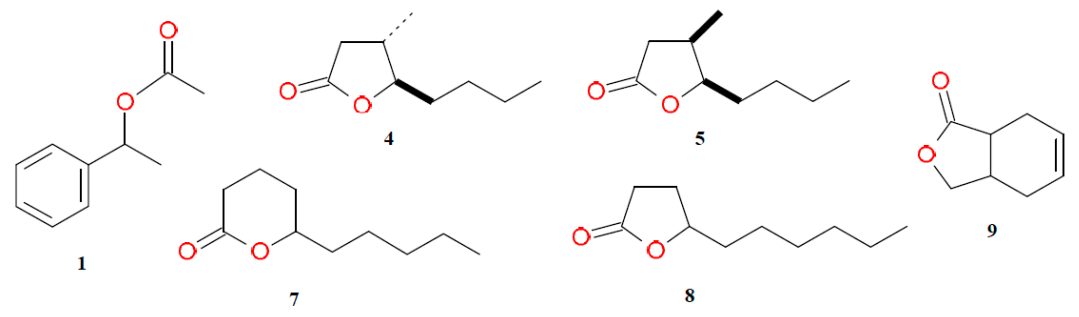

Scheme 1. Aroma compounds applied for kinetic resolution by solid-state fermentation (SSF).

\subsection{Kinetic Resolution of 1-Phenylethyl Acetate (1)}

Fungal strains exhibiting lipolytic activity were tested on racemic 1-phenylethyl acetate (1) as a reference substrate to investigate their capacity for dynamic kinetic resolution (Scheme 2). This substrate was hydrolyzed to phenylethanol (2), which is, especially in its enantiomerically pure forms, in great demand in the agrochemical, flavor, and pharmaceutical industries [20]. Additionally, as a result of alcohol 2 oxidation, acetophenone (3) was formed. In the biotransformation of racemic 1-phenylethyl acetate (1), both hydrolases and oxidoreductases play a crucial role. On the basis of gas chromatography (GC) analysis, arising acetophenone (3) during the biotransformation suggests that (S)-1-phenylethanol (2) is oxidized to acetophenone (3), which is immediately selectively reduced to (R)-1-phenylethanol (2).<smiles>CC(=O)OC(C)c1ccccc1</smiles>

Scheme 2. Kinetic resolution of 1-phenylethyl acetate (1).

The majority of the biocatalysts preferentially transformed the $(R)-\mathbf{1}$ ester to the corresponding (R)-2 alcohol (Table 1). Kinetic resolution of ester $\mathbf{1}$ catalyzed by all nine strains (Aspergillus candidus AM386, A. nidulans AM243, Botrytis cirenea AM235, Fusarium oxysporum AM21, F. semitectum AM20, Mucor spinosus AM398, Papularia rosea AM17, Penicillum camemberti AM83, Poria placenta AM38) of filamentous fungi tested produced $(S)-\mathbf{1}$ and $(R)-\mathbf{2}$, with a high conversion rate and enantiomeric excess. The greatest quantity of enantiomerically pure $(S)-\mathbf{1}$ (ee $>99 \%$ ) was achieved after three days of hydrolysis catalyzed by F. oxysporum AM21. Three strains (A. nidulans AM243, P. camemberti AM83, and F. avenaceum AM11) produced the $(R)-2$ enantiomer (ee $>99 \%$ ). Hydrolysis on RC proceeded relatively fast, and the highest enantioselectivity was achieved after three days of biotransformation. Subsequently, enantiomeric excess of product $(R)-2$ decreased. With application of $B$. cirenea AM235 and $P$. rosea AM17, high enantiomeric excess was observed, even after 10 days; however, in $P$. rosea AM17 culture the amount of acetophenone (3) increased steadily with time (data not shown).

LC was also a valuable biotransformation medium; however, hydrolysis proceeded via different pathways (Table 2). Hydrolysis of 1 with B. cirenea AM235 on LC provided the (S)-enantiomer of substrate 1, whereas on RC, the (R)-enantiomer of product 2 was produced (Table 1). Culture of A. ochraceus AM370 and Penicillium thomi AM91 produced only ketone 3, which suggests high oxidoreductase activity of these strains. Biotransformation catalyzed by Fusarium avenaceum AM11 also produced different results, with only ketone 3 or alcohol 2 observed on RC and LC, respectively. It is worthy of mention that the type of oilseed cake influenced enzyme activity and specificity. However, the use of another medium had no or only a slight influence on the kinetic resolution process catalyzed by A. nidulans AM243, A. ochraceus AM370, M. spinosus AM398, P. rosea AM17 in comparison to RC (Table 1). 
Table 1. Kinetic resolution of racemic 1-phenylethyl acetate (1) by fungi in rapeseed cake (in \% according to GC).

\begin{tabular}{|c|c|c|c|c|c|c|c|c|}
\hline \multirow{2}{*}{ Strain } & \multirow{2}{*}{$\begin{array}{l}\text { Time } \\
\text { (Days) }\end{array}$} & \multirow{2}{*}{$\begin{array}{c}\text { Lipase Activity } \\
\text { (U/g) }\end{array}$} & \multirow{2}{*}{$\begin{array}{c}\text { Conversion } \\
(\%)\end{array}$} & \multicolumn{2}{|c|}{ (S)-1 } & \multicolumn{2}{|c|}{$(R)-2$} & \multirow{2}{*}{$\begin{array}{c}3 \\
(\%)\end{array}$} \\
\hline & & & & $(\%)$ & ee $(\%)$ & $(\%)$ & ee $(\%)$ & \\
\hline Aspergillus candidus AM386 & 3 & 40.4 & 100 & 0 & - & 86 & $>99$ & 14 \\
\hline Aspergillus nidulans AM243 & 3 & 106.6 & 100 & 0 & - & 100 & $>99$ & 0 \\
\hline Aspergillus ochraceus AM370 & 3 & 21 & 100 & 0 & - & 0 & - & 100 \\
\hline Aspergillus ochraceus AM456 & 3 & 90.3 & 88 & 12 & 74 & 88 & 22 & 0 \\
\hline Aspergillus wenthi AM413 & 3 & 96.8 & 30 & 70 & 30 & 26 & 64 & 4 \\
\hline Botrytis cirenea AM235 & 6 & 144.7 & 100 & 0 & - & 96 & 98 & 4 \\
\hline Fusarium avenaceum AM11 & 3 & 46 & 100 & 0 & - & 0 & - & 100 \\
\hline Fusarium oxysporum AM21 & 3 & 146.5 & 18 & 82 & $>99$ & 15 & 44 & 3 \\
\hline Fusarium semitectum AM20 & 3 & 105.5 & 96 & 4 & $>99 \mathrm{a}$ & 56 & $>99$ & 40 \\
\hline Fusarium tricinctum AM16 & 3 & 67 & 25 & 75 & 20 & 25 & 66 & 0 \\
\hline Mucor spinosus AM398 & 3 & 54.1 & 94 & 6 & $66^{\mathrm{a}}$ & 78 & $>99$ & 16 \\
\hline Papularia rosea AM17 & 6 & 160.7 & 97 & 3 & 0 & 88 & 96 & 9 \\
\hline Penicillum camemberti AM83 & 3 & 144.3 & 100 & 0 & - & 100 & $>99$ & 0 \\
\hline Penicillium chrysogenum AM112 & 6 & 105.1 & 100 & 0 & - & 100 & 62 & 0 \\
\hline Penicillium thomi AM91 & 6 & 155.5 & 98 & 2 & $>99$ a & 60 & 54 & 38 \\
\hline Poria placenta AM38 & 10 & 22.1 & 98 & 2 & $>99$ a & 84 & 92 & 14 \\
\hline Spicoria divaricata AM423 & 3 & 89.9 & 93 & 7 & $>99$ & 59 & 0 & 34 \\
\hline
\end{tabular}

${ }^{\mathrm{a}}$ The reaction proceeded with opposite enantiomer selectivity $((R)-\mathbf{1})$.

Table 2. Kinetic resolution of racemic 1-phenylethyl acetate (1) by fungi in linseed cake (in \% according to GC).

\begin{tabular}{|c|c|c|c|c|c|c|c|c|}
\hline \multirow{2}{*}{ Strain } & \multirow{2}{*}{$\begin{array}{l}\text { Time } \\
\text { (Days) }\end{array}$} & \multirow{2}{*}{$\begin{array}{c}\text { Lipase Activity } \\
\text { (U/g) }\end{array}$} & \multirow{2}{*}{$\begin{array}{c}\text { Conversion } \\
(\%)\end{array}$} & \multicolumn{2}{|c|}{$(S)-1$} & \multicolumn{2}{|c|}{$(R)-2$} & \multirow{2}{*}{$\begin{array}{c}3 \\
(\%)\end{array}$} \\
\hline & & & & $(\%)$ & ee $(\%)$ & $(\%)$ & ee $(\%)$ & \\
\hline Aspergillus nidulans AM243 & 3 & 106.6 & 100 & 0 & - & 100 & $>99$ & 0 \\
\hline Aspergillus ochraceus AM370 & 3 & 21 & 100 & 0 & - & 0 & - & 100 \\
\hline Aspergillus ochraceus AM456 & 3 & 90.3 & 83 & 17 & 40 & 83 & 30 & 0 \\
\hline Aspergillus wenthi AM413 & 10 & 237.5 & 90 & 10 & 24 & 78 & 0 & 12 \\
\hline Botrytis cirenea AM235 & 3 & 14 & 10 & 90 & 80 & 0 & - & 10 \\
\hline Fusarium avenaceum AM11 & 3 & 46 & 100 & 0 & - & 100 & $>99$ & 0 \\
\hline Fusarium oxysporum AM21 & 10 & 26.6 & 75 & 25 & 62 & 59 & 0 & 16 \\
\hline Fusarium semitectum AM20 & 3 & 105.5 & 70 & 30 & 72 & 34 & 38 & 36 \\
\hline Fusarium tricinctum AM16 & 3 & 67 & 44 & 56 & 26 & 22 & 86 & 22 \\
\hline Mucor spinosus AM398 & 3 & 54.1 & 100 & 0 & 0 & 95 & 90 & 5 \\
\hline Papularia rosea AM17 & 6 & 160.7 & 100 & 0 & 0 & 46 & 86 & 54 \\
\hline Penicillum camemberti AM83 & 3 & 144.3 & 30 & 70 & 30 & 30 & 58 & 0 \\
\hline Penicillium chrysogenum AM112 & 6 & 105.1 & 92 & 8 & $>99$ & 67 & 50 & 25 \\
\hline Penicillium notatum AM904 & 6 & 36.5 & 100 & 0 & 0 & 92 & 0 & 8 \\
\hline Penicillium thomi AM91 & 3 & 39.4 & 100 & 0 & - & 0 & - & 100 \\
\hline Sclerophoma pythiophila AR55 & 3 & 5.6 & 48 & 52 & 52 & 35 & 20 & 13 \\
\hline Spicoria divaricata AM423 & 3 & 20.1 & 100 & 0 & - & 85 & 26 & 15 \\
\hline
\end{tabular}

Both media, RC and LC, were effective for lipase production. In general, higher lipase activity was observed in most cultures grown on RC, however three strains A. ochraceus AM370, A. wenthi AM413, and F. avenaceum AM11 exhibited higher lipase activity on LC. Previous reports describe a few examples of use of these oilseed cakes as a medium for hydrolase production [6,21-25]. When considering the differences in the kinetic resolution results, it appears that the chemical composition of the media induces the production of enzymes with different enantioselectivity. Fermentation on LC produced a greater content of carbohydrates and proteins as compared to RC, although the quantity of residual oil was comparable (12-13\%) [26-28]. The main differences in LC and RC are in fatty acid composition, which can strongly affect lipase biosynthesis. Both LC and RC contain a significant majority of unsaturated fatty acids (90-94\%). However, in LC, $\alpha$-linolenic acid predominates (50-55\%), whereas RC primarily contains oleic acid ( $60 \%)$, and only $1 \% \alpha$-linolenic acid. Oilseed cake from flax contains a similar linoleic acid content $(\sim 20 \%)$ to RC $[29,30]$. Moreover, the physical properties of LC, which shows significantly stronger adsorption of water (used to add moisture in SSF) than RC, might explain the differences in the efficiency of the fungal kinetic resolution process [31]. It is worth 
mentioning that during the SSF processes that were conducted in this experiment, not only hydrolases were produced. Acetophenone (3) was synthesized by oxidoreductases, which have not been assessed in SSF to date.

A few examples of fungal kinetic resolution, although in submerged fermentation, of ester 1 can be found in recent literature [32,33]. Fusarium proliferatum NCIM1105 used for hydrolytic kinetic resolution of racemic 1 afforded $100 \%$ enantiomerically pure $(R)-2$ within $36 \mathrm{~h}$ [33]. In the present study, comparable results were obtained with A. nidulans AM243, P. camemberti AM83, and F. avenaceum AM11 (Tables 1 and 2). Filamentous fungi Aspergillus flavus CECT20475 was applied in kinetic resolution of 2. Within 24 h at $40{ }^{\circ} \mathrm{C},(R)-2$ was esterified into $(R)-1$ with ee $=94.6 \%$, and ee $=99 \%$ of $(S)-2$ was received [34]. Nagy et al. screened filamentous fungi under SSF for lipase activity and enantioselectivity relative to 1, using wheat bran as a medium [19]. Of the 26 fungal strains that were tested, 18 were able to provide $(R)-\mathbf{2}$ with high enantiomeric excess (ee $>88 \%$ ). Six strains hydrolyzed $\mathbf{1}$ to produce $(S)-\mathbf{1}$ with ee $>83 \%$. Enantiomerically pure $(R)-2$ was obtained with Chaetomium elatum UAMH2672 and Scopulariopsis brevicaulis WFPL248A as a biocatalysts within $24 \mathrm{~h}$, and (S)-1 was received within $120 \mathrm{~h}$ with ee $>99 \%$ by Chaetomium globosum OKI270 and Gliocladium vermoesenii NRRL1752. Resolution of racemic 1 by Candida antarctica lipase B was examined by Fan et al. [35]. As a result, racemic 1 was hydrolyzed with the conversion rate $41.2 \%$ and enantiomerically pure (S)-2 was obtained. Liang et al. [36] applied esterase from Bacillus sp. SCSIO 15121 to obtain $(R)-2$ with the conversion rate $49 \%$. Application of the enzymatic system of vegetables to the kinetic resolution of 1 was reported by Vanderberghe et al. [37]. The highest ee of hydrolysis products was obtained by using beetroot as a biocatalyst (ee of $(R)-\mathbf{2} 66 \%,(S)-1>99 \%)$. Purified microbial GDSL lipase MT6 conduct hydrolysis of 1 within $12 \mathrm{~h}$ and generated $(S)-2$ with ee $=97 \%$, however the conversion rate was $28 \%$ [38].

\subsection{Kinetic Resolution of trans and cis Whisky Lactones $(\mathbf{4}, \mathbf{5})$}

SSF has not previously been applied to obtain enantiomerically pure whisky lactone, one of the most commonly used flavors in the food industry. Each enantiomer displays different biological activity, due to its structural characteristics. Therefore, it is important to evaluate the natural and economical methods of production of enantiomerically pure forms of whisky lactone. Currently, a few biotechnological methods that produce enantiomerically pure cis and trans isomers of whisky lactone are known. Trans-(-)-(4R,5S)- and cis-(+)-(4R,5R)-whisky lactones can be produced by enantioselective oxidation of diols using alcohol dehydrogenases, mainly horse liver alcohol dehydrogense (HLADH) as biocatalysts. Thereafter, $(-)-(4 R, 5 S)$-isomer with yield $=51 \%$ and ee $=34 \%$, as well as $(+)-(4 R, 5 R)$-isomer with yield $=48 \%$ and ee $=64 \%$ were formed after $24 \mathrm{~h}$. In the same study, filamentous fungi were used to catalyze lactonization of $\gamma$-oxoacids. Transformation catalyzed by Beauveria bassiana AM278 provide after $48 \mathrm{~h}$ trans-(+)-(4S,5R)-whisky lactone (yield $=55 \%$ and ee $>99 \%$ ) and cis- $(-)-(4 S, 5 S)$ (yield $=45 \%$ and ee $=77 \%$ ) [39].

Kinetic resolution of a diastereoisomeric mixture of whisky lactones was conducted on RC and LC (Scheme 3), similar to the previous substrate 1. Filamentous fungi mainly catalyzed hydrolysis of (-)-(4R,5S)-4 and (-)-(4S,5S)-5 to the corresponding hydroxyacid $\mathbf{6}$, leaving (+)-(4S,5R)-4 and $(+)-(4 R, 5 R)-5$ predominantly.

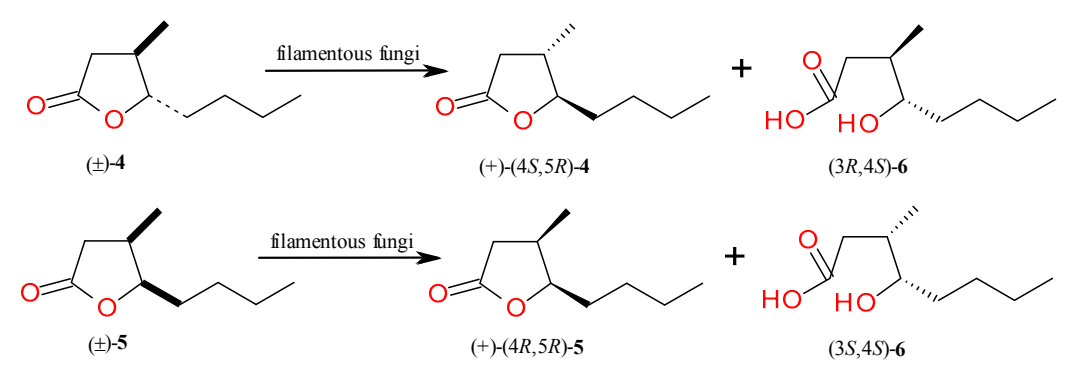

Scheme 3. Kinetic resolution of diastereoisomeric mixture of whisky lactones $(4,5)$. 
Tables 3 and 4 list the fungi that most effectively hydrolyzed 4 and 5 on LC and RC. The selected filamentous fungi exhibited biocatalytic ability to hydrolyze the internal ester bond in trans and cis whisky lactones.

Table 3. Kinetic resolution of mixture of racemic trans and cis whisky lactones $(4,5)$ by filamentus fungi in rapeseed cake (in \% according to GC).

\begin{tabular}{lccccc}
\hline \multicolumn{1}{c}{ Strain } & $\begin{array}{c}\text { Time } \\
\text { (Days) }\end{array}$ & $\begin{array}{c}\text { Lipase Activity } \\
\text { (U/g) }\end{array}$ & $\begin{array}{c}\text { trans/cis } \\
\text { Ratio (\%) }\end{array}$ & $\begin{array}{c}\text { trans-(+)-(4S,5R)-4 } \\
\text { ee (\%) }\end{array}$ & $\begin{array}{c}\text { cis-(+)-(4R,5R)-5 } \\
\text { ee (\%) }\end{array}$ \\
\hline Aspergillus sp. AM31 & 6 & 18.1 & $59 / 41$ & 38 & 28 \\
Fusarium culmorum AM9 & 3 & 3 & $48 / 52$ & 12 & 14 \\
Fusarium equiseti AM15 & 3 & 5.8 & $50 / 50$ & 24 a & 18 \\
Fusarium oxysporum AM13 & 6 & 25 & $56 / 44$ & 56 & 60 \\
Papularia rosea AM17 & 6 & 160.7 & $33 / 67$ & 70 & 42 \\
Penicillum camemberti AM83 & 3 & 144.3 & $77 / 23$ & 32 & 0 \\
Penicillium chrysogenum AM112 & 10 & 49.2 & $77 / 23$ & 42 & 14 \\
Penicillium notatum AM904 & 6 & 36.5 & $58 / 42$ & 52 & 0 \\
Pycnidiella resinae AR50 & 6 & 19.8 & $27 / 73$ & 40 & 0 \\
\hline
\end{tabular}

a The reaction proceeded with opposite enantiomer selectivity ((-)-(4R,5S)-4).

Table 4. Kinetic resolution of mixture of racemic trans and cis whisky lactones $(4,5)$ by fungi in linseed cake (in \% according to GC).

\begin{tabular}{lccccc}
\hline \multicolumn{1}{c}{ Strain } & $\begin{array}{c}\text { Time } \\
\text { (Days) }\end{array}$ & $\begin{array}{c}\text { Lipase Activity } \\
\text { (U/g) }\end{array}$ & $\begin{array}{c}\text { trans/cis } \\
\text { Ratio (\%) }\end{array}$ & $\begin{array}{c}\text { trans-(+)-(4S,5R)-4 } \\
\text { ee (\%) }\end{array}$ & $\begin{array}{c}\text { cis-(+)-(4R,5R)-5 } \\
\text { ee (\%) }\end{array}$ \\
\hline Aspergillus nidulans AM243 & 6 & 47.2 & $46 / 54$ & 90 & 0 \\
Aspergillus ochraceus AM456 & 6 & 15.4 & $65 / 35$ & 0 & 14 \\
Fusarium avenaceum AM11 & 6 & 61.8 & $52 / 48$ & 90 & 14 \\
Fusarium semitectum AM20 & 6 & 87 & $40 / 60$ & 26 & 38 \\
Fusarium solani AM203 & 6 & 87.4 & $54 / 46$ & 90 & 52 \\
Penicillum camembertii AM83 & 6 & 118 & $35 / 65$ & 84 & 0 \\
Penicillium chrysogenum AM112 & 6 & 105.1 & $54 / 46$ & 44 & 0 \\
Penicillium notatum AM94 & 6 & 36.5 & $65 / 35$ & 50 & 10 \\
Penicillium vermiculatum AM30 & 10 & 3.2 & $55 / 45$ & 40 & 12 \\
Sclerophoma pythiophila AM55 & 6 & 9.9 & $56 / 44$ & 28 & \\
\hline
\end{tabular}

Following fungal kinetic resolution of diastereoisomeric mixtures of whisky lactones (4 and 5 ), enantiomerically enriched isomers (+)-(4S,5R)-4, and (+)-(4R,5R)-5 were obtained. Most of the filamentous fungi exhibited a strong tendency to hydrolyze both diastereoisomers of whisky lactone. However, a greater enantiomeric excess of $(+)-(4 S, 5 R)-4$ was observed on LC. After six days of SSF, A. nidulans AM243, F. avenaceum AM11, and F. solani AM203 afforded 4 with ee $=90 \%$ (Table 4 ). Notably, SSF with F. solani AM203 afforded enantiomerically enriched both diastereoisomers (ee $=90 \%$ of 4 and ee $=52 \%$ of 5 ). This strain showed the highest enantioselectivity for both isomers among all of the screened strains. Further studies of medium optimization for F. solani AM203 will be undertaken in the near future. Biotransformation on RC was characterized by lower enantioselectivity in comparison to LC. As biotransformation progressed, kinetic resolution of $\mathbf{4}$ and $\mathbf{5}$ did not improve. The best results were achieved by F. oxysporum AM13 and P. rosea AM17, which hydrolyzed 4 with ee $=56 \%$ and $70 \%$ and 5 with ee $=60 \%$ and $42 \%$, respectively.

\subsection{Kinetic Resolution of $\gamma$-Decalactone (7) and $\delta$-Decalactone (8)}

During SSF of $\gamma$-decalactone (7) and $\delta$-decalactone (8), both of the substrates were metabolized and probably assimilated by the microorganisms as a source of energy. Therefore, application of oilseed cake as a medium for enantioselective hydrolysis of these lactones is not reasonable. A method for obtaining enantiomerically enriched $\gamma$ - and $\delta$-decalactones by applying alcohol dehydrogenases to enzymatic oxidation of diols was presented by us previously [40]. Enzyme HLADH after two days catalyzed the oxidation of diol to the $(-)-(S)$-isomer of $\gamma$-decalactone with yield $=79 \%$ and 
ee $=20 \%$, while PADH III after five days mediated oxidation gave $(+)-(R)$-isomer of $\gamma$-decalactone with significantly higher enantiomeric excess, but lower yield (yield $=16 \%$ and ee $=80 \%$ ).

\subsection{Kinetic Resolution of cis-3a,4,7,7a-Tetrahydro-1(3H)-isobenzofuranone (9)}

Fungal kinetic resolution of 9 in SSF on RC and LC was studied. All of the strains hydrolyzed only $(+)-(3 a S, 7 a R)-9$, whereby only $(-)-(3 a R, 7 a S)-9$ was obtained in high enantiomeric excess (Scheme 4$)$. Table 5 shows the results of hydrolysis of 9 .<smiles>O=C1OCC2CC=CCC12</smiles>

$( \pm)^{-9}$<smiles>O=C1OC[C@H]2CC=CC[C@H]12</smiles>

(-)-(3aR,7aS)-9<smiles>O=C(O)[C@H]1CC=CC[C@H]1CO</smiles>

10

Scheme 4. Enantioselective hydrolysis of lactone 9.

Table 5. Kinetic resolution of racemic lactone 9 by fungi in SSF (in \% according to GC).

\begin{tabular}{lcccc}
\hline \multicolumn{1}{c}{ Strain } & Time (Days) & Lipase Activity (U/g) & \multicolumn{2}{c}{ (-)-(3aR,7aS)-9 ee (\%) } \\
\cline { 3 - 5 } & & & RC & LC \\
\hline Aspergillus nidulans AM243 & 3 & 106.6 & 34 & 26 \\
Aspergillus wenthi AM413 & 3 & 96.8 & 50 & 0 \\
Botrytis cirenea AM235 & 6 & 144.7 & 0 & 80 \\
Fusarium avenaceum AM11 & 3 & 46 & 10 & 20 \\
Fusarium oxysporum AM21 & 3 & 146.5 & 74 & 16 \\
Fusarium semitectum AM20 & 3 & 105.5 & 66 & 44 \\
Fusarium tricinctum AM16 & 3 & 67 & 12 & 68 \\
Mucor spinosus AM398 & 3 & 54.1 & 38 & 40 \\
Papularia rosea AM17 & 6 & 160.7 & 26 & 10 \\
Penicillum camembertii AM83 & 3 & 144.3 & 34 & 34 \\
Penicillium chrysogenum AM112 & 6 & 105.1 & 36 & 50 \\
Penicillium notatum AM904 & 6 & 36.5 & 20 & 82 \\
Sclerophoma pythiophila AM55 & 3 & 5.6 & 26 & 24 \\
Spicoria divaricata AM423 & 3 & 20.1 & & 0 \\
\hline
\end{tabular}

The highest enantioselectivity of hydrolysis of 9 was observed using P. notatum AM904 and B. cirenea AM235 as biocatalysts (ee $=82 \%$ and $80 \%$, respectively) on LC. However, a modest enantiomeric excess of the (-)-(3aR,7aS)-9 isomer was also obtained by F. oxysporum AM21 and F. semitectum AM20 on RC (ee $=74 \%$ and $66 \%$, respectively). Using the previous substrates $(1,4)$, the application of LC or RC resulted also in significant differences in hydrolysis of 9. B. cinerea AM235 stereoselectively catalyzed hydrolysis of 9 only on LC, producing the $(-)$ isomer in high enantiomeric excess (ee $=80 \%$ ). F. oxysporum AM21 afforded the $(-)$ isomer of 9 with ee $=74 \%$ on RC, in comparison to LC, where the enantiomeric excess was only $16 \%$. In an alternative method applied by our group, based on bacterial oxidation of the corresponding diol, enantiomerically enriched $(-)-(3 \mathrm{a} R, 7 \mathrm{a} S)-9$ isomer was produced by Micrococcus sp. DSM 30771 after seven days with the yield $=28 \%$ in comparable enantiomeric excess $(e e=88 \%)[41]$.

\section{Materials and Methods}

\subsection{Materials}

Rapeseed and linseed cakes were purchased from Oleofarm, Wroclaw, Poland. 1-Phenylethyl acetate (1), trans and cis whisky lactones $(\mathbf{4}, 5), \gamma$-decalactone (7), $\delta$-decalactone (8), and $p$-nitrophenyl 
palmitate ( $p$-NPP) were purchased from Sigma-Aldrich Chemical Co. (St. Louis, MO, USA). Racemic lactone cis-3a,4,7,7a-tetrahydro-1(3H)-isobenzofuranone (9) was synthesized according to described procedure [42].

\subsection{Microorganisms}

The following filamentous fungi strains were used for screening: Aspergillus sp. AM31, Aspergillus candidus AM386, Aspergillus nidulans AM243, Aspergillus ochraceus AM370, Aspergillus ochraceus AM456, Aspergillus wenthi AM413, Botrytis cirenea AM235, Fusarium avenaceum AM11, Fusarium culmorum AM9, Fusarium equiseti AM15, Fusarium oxysporum AM13, Fusarium oxysporum AM21, Fusarium semitectum AM20, Fusarium tricinctum AM16, Fusarium solani AM203, Mucor spinosus AM398, Papularia rosea AM17, Penicillum camembertii AM83, Penicillium chrysogenum AM112, Penicillium notatum AM904, Penicillium thomi AM91, Penicillium vermiculatum AM30, Poria placenta AM38, Pycnidiella resinae AR50, Sclerophoma pythiophila AR55, Spicoria divaricata AM423. The microorganisms were purchased from Department of Chemistry, Wroclaw University of Environmental and Life Sciences (Wroclaw, Poland). They were stored at $4{ }^{\circ} \mathrm{C}$ on Sabouraud agar slants containing peptone $(10 \mathrm{~g})$, glucose $(30 \mathrm{~g})$ and agar $(15 \mathrm{~g})$ dissolved in water (1 L) at $\mathrm{pH} 5.5$.

\subsection{Solid-State Fermentation}

Oilseed cakes were placed ( $5 \mathrm{~g}$ each) in Erlenmayer flasks and autoclaved for $15 \mathrm{~min}$ at $121^{\circ} \mathrm{C}$. Then, hydrated to $60 \%$ moisture, inoculated with $0.5 \mathrm{~mL}$ of a dense spore suspension $2.3 \times 10^{7}$ spores $/ \mathrm{mL}$ prepared in sterile water from agar slant cultures, and thoroughly mixed. Flasks were then incubated in thermostatic cabinet at $30^{\circ} \mathrm{C}$ with defined humidity and without shaking.

\subsection{Enzyme Extraction and Activity Assay}

Samples ( $3 \mathrm{~g})$ of solid-state media were taken at specified interval of cultivation time $(3,6$, and 10 days), then vortexed for $5 \mathrm{~min}$ at $3500 \mathrm{rpm}$ in phosphate buffer $\mathrm{pH} 7.2$, centrifuged at 10,000 rpm for $10 \mathrm{~min}$ at room temperature, and supernatants were assayed for lipase activity. Lipase activity was determined in a spectrophotometric assay with $p$-NPP as a substrate. The enzyme reaction mixture contained $75 \mu \mathrm{L}$ of substrate $(1 \mathrm{mM})$ dissolved in isopropanol, $50 \mu \mathrm{L}$ of crude enzyme filled to $3 \mathrm{~mL}$ by $50 \mathrm{mM}$ Tris- $\mathrm{HCl}$ buffer ( $\mathrm{pH} 8)$ and incubated at $37^{\circ} \mathrm{C}$ for $10 \mathrm{~min}$. The reaction was interrupted by addition of $1 \mathrm{~mL}$ cooled ethanol. The activity was measured at $410 \mathrm{~nm}$. One enzyme unit (U) was defined as an amount of enzyme that released $1 \mu \mathrm{M} p$-nitrophenol per minute. Lipase activity was calculated using $p$-nitrophenol standard curve and was expressed in units/gram of oilseed cake.

\subsection{Biotransformation Process}

After three days of cultivation, grown cultures were sprayed by a $0.2 \mathrm{~mL} 5 \mathrm{mM}$ solution of substrates in acetone and water $(1: 1 v / v)$. For each biotransformation three individual flasks were set up to estimate the progress of reaction after 3,6 , and 10 days. To the samples distilled water $(15 \mathrm{~mL})$ and ethyl acetate $(5 \mathrm{~mL})$ were added. Media were vortexed for $5 \mathrm{~min}$ at $3500 \mathrm{rpm}$ and centrifuged at $5000 \mathrm{rpm}$ for $15 \mathrm{~min}$ at room temperature. Finally, the organic phase was dehydrated by anhydrous $\mathrm{MgSO}_{4}$ and transferred to a vial then analyzed on a gas GC instrument equipped with an autosampler (Figure 1). In control experiments, the substrates were incubated in sterile oilseed cakes without microorganism to check substrate stability. Additionally, to estimate the fungal metabolites, a control culture was performed without substrates. 


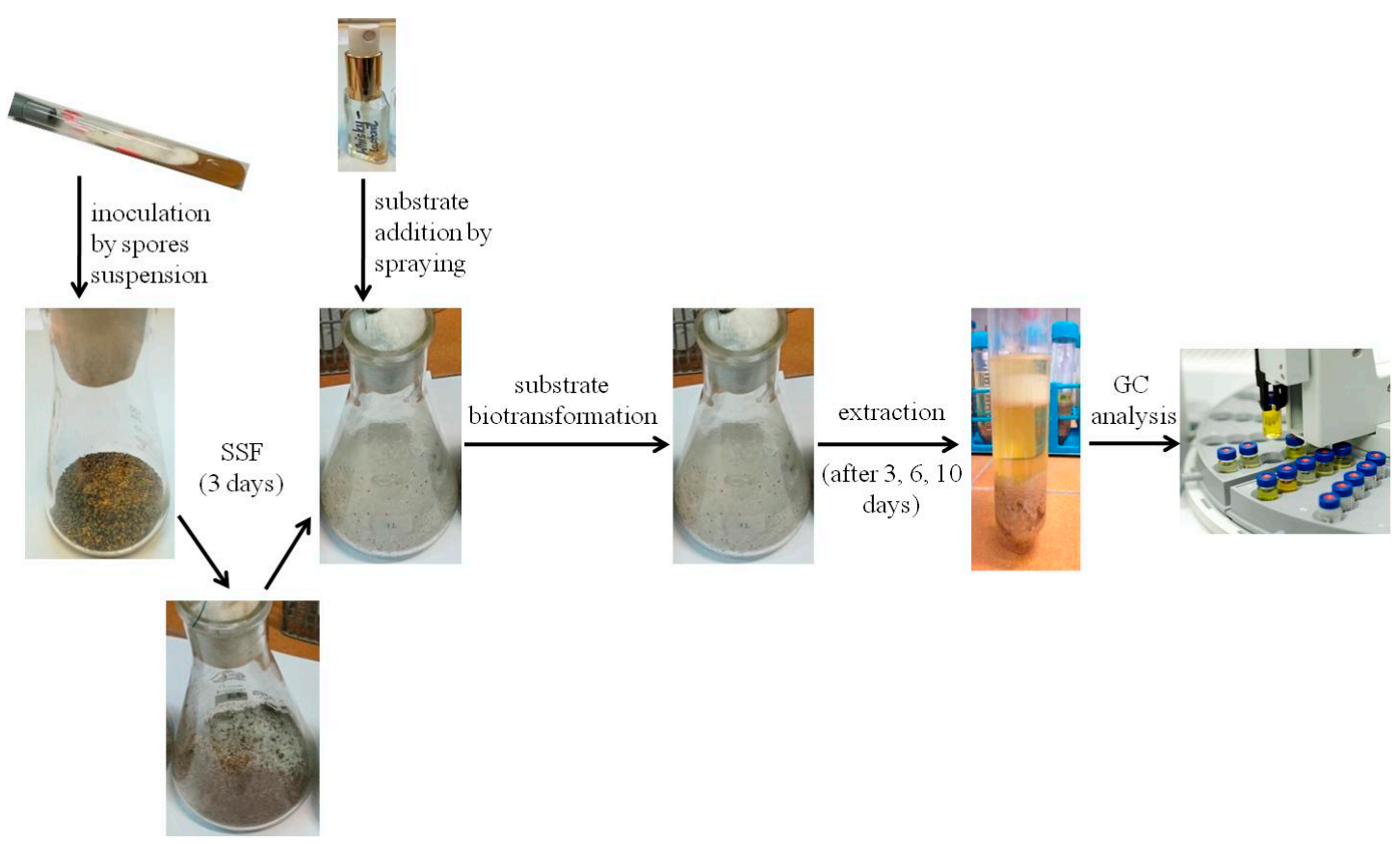

Figure 1. The process of aroma compounds kinetic resolution by using solid-state fermentation.

\subsection{Analysis}

The progress of reaction and enantiomeric excesses of the hydrolysis products were determined by gas chromatography. Determination of the individual isomers was based on previously obtained standards of chiral lactones [39-41]. Quantification was made when comparing with standard graph drawn for individual compounds. Gas chromatography analysis (FID, carrier gas $\mathrm{H}_{2}$ ) was carried out on Agilent Technologies 7890N (GC System, Agilent, Santa Clara, CA, USA). Enantiomeric excesses of the products 1-7 and 9 were determined on chiral column Cyclosil-B $(30 \mathrm{~m} \times 0.25 \mathrm{~mm} \times 0.25 \mu \mathrm{m})$, according the next temperature programs: $(1-3) 80^{\circ} \mathrm{C}, 110^{\circ} \mathrm{C}\left(1{ }^{\circ} \mathrm{C} / \mathrm{min}\right), 200^{\circ} \mathrm{C}\left(20^{\circ} \mathrm{C} / \mathrm{min}\right)(5 \mathrm{~min})$. The total run time was $39.5 \mathrm{~min}$. Retention times were established, as follow: $(S)-\mathbf{1}=28.1 \mathrm{~min}$, $(R)-\mathbf{1}=29.5 \mathrm{~min},(R)-\mathbf{2}=29.9 \mathrm{~min},(S)-2=30.8 \mathrm{~min}, 3=27.5 \mathrm{~min} ;(4,5) 80^{\circ} \mathrm{C}, 160{ }^{\circ} \mathrm{C}\left(3{ }^{\circ} \mathrm{C} / \mathrm{min}\right)$, $250{ }^{\circ} \mathrm{C}\left(20^{\circ} \mathrm{C} / \mathrm{min}\right)(3 \mathrm{~min})$. The total run time was $34.0 \mathrm{~min}$. Retention times were established as follow: (+)-(4S,5R)-4 = $21.70 \mathrm{~min} .,(-)-(4 R, 5 S)-4=22.01 \mathrm{~min},(-)-(4 S, 5 S)-5=23.45 \mathrm{~min},(+)-(4 R, 5 R)-5$ $=23.60 \mathrm{~min} ;(7) 80^{\circ} \mathrm{C}, 210{ }^{\circ} \mathrm{C}\left(8^{\circ} \mathrm{C} / \mathrm{min}\right), 250{ }^{\circ} \mathrm{C}\left(20^{\circ} \mathrm{C} / \mathrm{min}\right)(3 \mathrm{~min})$. The total run time was $21.0 \mathrm{~min}$. Retention times were established as follow: $(S)-7=14.53 \mathrm{~min},(R)-7=14.58 \mathrm{~min}$; $(9) 80^{\circ} \mathrm{C}, 160{ }^{\circ} \mathrm{C}$ $\left(2{ }^{\circ} \mathrm{C} / \mathrm{min}\right), 200{ }^{\circ} \mathrm{C}\left(20^{\circ} \mathrm{C} / \mathrm{min}\right)(6 \mathrm{~min})$. The total runtime was $48.0 \mathrm{~min}$. Retention times were established as follow: $(+)-(3 a S, 7 a R)-9=36.3 \mathrm{~min},(-)-(3 a R, 7 \mathrm{a} S)-9=36.6 \mathrm{~min}$. Column CP-Chirasil DEX $7502(30 \mathrm{~m} \times 0.25 \mathrm{~mm} \times 0.25 \mu \mathrm{m})$ was used to determine 8 , according to the next temperature program: $80^{\circ} \mathrm{C}, 120^{\circ} \mathrm{C}\left(0.5^{\circ} \mathrm{C} / \mathrm{min}\right), 200{ }^{\circ} \mathrm{C}\left(20^{\circ} \mathrm{C} / \mathrm{min}\right)(2 \mathrm{~min})$. The total run time was $86.0 \mathrm{~min}$. Retention times were established as follow: $(R)-8=73.8 \mathrm{~min},(S)-8=75.9 \mathrm{~min}$.

\section{Conclusions}

SSF cultures were evaluated for kinetic resolution of natural-identical aroma compounds. Agroindustrial side streams proved to be a wholesome growth medium for microorganisms that exhibit high enantioselectivity of hydrolysis of 1-phenylethyl acetate (1). Dynamic kinetic resolution of 1-phenylethyl acetate (1) catalyzed by F. oxysporum AM21 afforded enantiomerically pure (S)-1 (ee $>99 \%$ ). The ( $R$ )-enantiomer (ee $>99 \%$ ) of phenylethanol (2) was produced by A. nidulans AM243, P. camemberti AM83, and F. avenaceum AM11. Kinetic resolution of a diastereoisomeric mixture of whisky lactone (4 and 5) catalyzed by A. nidulans AM243, F. avenaceum AM11, and F. solani AM203 afforded trans-(+)-(4S,5R)-4 with ee $=90 \%$. The highest enantioselectivity of hydrolysis of the bicyclic 
lactone 9 was observed with P. notatum AM904 and B. cirenea AM235 (ee $=82 \%$ and ee $=80 \%$ respectively). In conclusion, enantiomerically enriched isomers of aroma lactones can be economically obtained using environmentally friendly techniques by the solid-state fermentation of oilseed cakes.

Acknowledgments: This work was supported by Wroclaw Centre of Biotechnology, programme The Leading National Research Centre (KNOW) for years 2014-2018. We would like to show our gratitude to the students, Malwina Dybiec, Anna Chryplewicz and Bartłomiej Skalny from Students Scientific Association OrgChem, who contributed to the research.

Author Contributions: F.B., E.S., T.O. and A.G. conceived and designed the experiments; E.S. performed the experiments; F.B. and E.S. analyzed the data; F.B. and E.S. wrote the paper.

Conflicts of Interest: The authors declare no conflict of interest.

\section{References}

1. Aggelopoulos, T.; Katsieris, K.; Bekatorou, A.; Pandey, A.; Banat, I.M.; Koutinas, A.A. Solid state fermentation of food waste mixtures for single cell protein, aroma volatiles and fat production. Food Chem. 2014, 145, 710-716. [CrossRef] [PubMed]

2. Kapilan, R. Solid state fermentation for microbial products: A review. Appl. Sci. Res. 2015, 7, $21-25$.

3. Castilho, L.R.; Polato, C.M.S.; Baruque, E.A.; Sant'Anna, G.L.; Freire, D.M.G. Economic analysis of lipase production by Penicillium restrictum in solid-state and submerged fermentations. Biochem. Eng. J. 2000, 4, 239-247. [CrossRef]

4. Joo, H.S.; Kumar, C.G.; Park, G.C.; Paik, S.R.; Chang, C.S. Oxidant and SDS-stable alkaline protease from Bacillus clausii I-52: Production and some properties. J. Appl. Microbiol. 2003, 95, 267-272. [CrossRef] [PubMed]

5. Salihu, A.; Alam, Z.; Abdulkarim, M.I.; Salleh, H.M. Resources, conservation and recycling lipase production: An insight in the utilization of renewable agricultural residues. Resour. Conserv. Recycl. 2012, 58, 36-44. [CrossRef]

6. De Castro, R.J.S.; Sato, H.H. Enzyme production by solid state fermentation: General aspects and an analysis of the physicochemical characteristics of substrates for agro-industrial wastes valorization. Waste Biomass Valoriz. 2015, 6, 1085-1093. [CrossRef]

7. Muñoz Solano, D.; Hoyos, P.; Hernáiz, M.J.; Alcántara, A.R.; Sánchez-Montero, J.M. Industrial biotransformations in the synthesis of building blocks leading to enantiopure drugs. Bioresour. Technol. 2012, 115, 196-207. [CrossRef] [PubMed]

8. Fuhshuku, K.; Oda, S.; Sugai, T. Enzyme reactions as the key step in the synthesis of terpenoids, degraded cartoenoids, steroids, and related substances. Recent Res. Dev. Org. Chem. 2002, 6, 57-74.

9. Etschmann, M.; Bluemke, W.; Sell, D.; Schrader, J. Biotechnological production of 2-phenylethanol. Appl. Microbiol. Biotechnol. 2002, 59, 1-8. [CrossRef] [PubMed]

10. Serra, S.; Fuganti, C.; Brenna, E. Biocatalytic preparation of natural flavours and fragrances. Trends Biotechnol. 2005, 23, 193-198. [CrossRef] [PubMed]

11. Pisani, L.; Superchi, S.; D'Elia, A.; Scafato, P.; Rosini, C. Synthetic approach toward cis-disubstituted $\gamma-$ and $\delta$-lactones through enantioselective dialkylzinc addition to aldehydes: Application to the synthesis of optically active flavors and fragrances. Tetrahedron 2012, 68, 5779-5784. [CrossRef]

12. Brenna, E.; Fuganti, C.; Gatti, F.G.; Serra, S. Biocatalytic methods for the synthesis of enantioenriched odor active compounds. Chem. Rev. 2011, 111, 4036-4072. [CrossRef] [PubMed]

13. Krings, U.; Berger, R.G. Biotechnological production of flavours and fragrances. Appl. Microbiol. Biotechnol. 1998, 49, 1-8. [CrossRef] [PubMed]

14. Okui, S.; Uchiyama, M.; Mizugaki, M. Metabolism of hydroxy fatty acids II. Intermediates of the oxidative breakdown acid by genus Candida. J. Biochem. 1963, 54, 536-540. [CrossRef] [PubMed]

15. Van der Schaft, P.H.; ter Burg, N.; van den Bosch, S.; Cohen, A.M. Microbial production of natural $\delta$-decalactone and $\delta$-dodecalactone from the corresponding $\alpha, \beta$-unsaturated lactones in Massoi bark oil. Appl. Microbiol. Biotechnol. 1992, 36, 712-716. [CrossRef]

16. Beck, J.J.; Chou, S.C. The structural diversity of phthalides from the Apiaceae. J. Nat. Prod. 2007, 70, 891-900. [CrossRef] [PubMed] 
17. Gassenmeier, K.; Schwager, H.; Houben, E.C.R. Unequivocal identification of 1-phenylethyl acetate in clove buds (Syzygium aromaticum L.). Foods 2017, 6, 46. [CrossRef]

18. Alves Macedo, G.; Soberón Lozano, M.M.; Pastore, G.M. Enzymatic synthesis of short chain citronellyl esters by a new lipase from Rhizopus sp. Electron. J. Biotechnol. 2003, 6, 69-72. [CrossRef]

19. Nagy, V.; Toke, E.R.; Keong, L.C.; Szatzker, G.; Ibrahim, D.; Omar, I.C.; Szakács, G.; Poppe, L. Kinetic resolutions with novel, highly enantioselective fungal lipases produced by solid state fermentation. J. Mol. Catal. B Enzym. 2006, 39, 141-148. [CrossRef]

20. Kamble, M.P.; Chaudhari, S.A.; Singhal, R.S.; Yadav, G.D. Synergism of microwave irradiation and enzyme catalysis in kinetic resolution of $(R, S)$-1-phenylethanol by cutinase from novel isolate Fusarium ICT SAC1. Biochem. Eng. J. 2017, 117, 121-128. [CrossRef]

21. Amin, M.; Bhatti, H.N. Effect of physicochemical parameters on lipase production by Penicillium fellutanum using canola seed oil cake as substrate. Int. J. Agric. Biol. 2014, 16, 118-124.

22. Freitas, A.C.; Castro, R.J.S.; Fontenele, M.A.; Egito, A.S.; Farinas, C.S.; Pinto, G.A.S. Canola cake as a potential substrate for proteolytic enzymes production by a selected strain of Aspergillus oryzae: Selection of process conditions and product characterization. ISRN Microbiol. 2013, 2013, 1-8. [CrossRef] [PubMed]

23. De Castro, A.M.; De Andréa, T.V.; Carvalho, D.F.; Teixeira, M.M. P.; Dos Reis Castilho, L.; Freire, D.M.G. Valorization of residual agroindustrial cakes by fungal production of multienzyme complexes and their use in cold hydrolysis of raw starch. Waste Biomass Valoriz. 2011, 2, 291-302. [CrossRef]

24. Rehman, S. Optimization of process parameters for enhanced production of lipase by Penicillium notatum using agricultural wastes. Afr. J. Biotechnol. 2011, 10, 19580-19589. [CrossRef]

25. Tan, T.; Zhang, M.; Xu, J.; Zhang, J. Optimization of culture conditions and properties of lipase from Penicillium camembertii Thom PG-3. Process Biochem. 2004, 39, 1495-1502. [CrossRef]

26. Ramachandran, S.; Singh, S.K.; Larroche, C.; Soccol, C.R.; Pandey, A. Oil cakes and their biotechnological applications-A review. Bioresour. Technol. 2007, 98, 2000-2009. [CrossRef] [PubMed]

27. Mueller, K.; Eisner, P.; Yoshie-Stark, Y.; Nakada, R.; Kirchhoff, E. Functional properties and chemical composition of fractionated brown and yellow linseed meal (Linum usitatissimum L.). J. Food Eng. 2010, 98, 453-460. [CrossRef]

28. Sivaramakrishnan, S.; Gangadharan, D. Edible Oil Cakes. In Biotechnology for Agro-Industrial Residues Utilisation; Singh nee' Nigam, P., Pandey, A., Eds.; Springer: New Delhi, India, 2009; pp. 253-271, ISBN 978-1-4020-9942-7.

29. Orsavova, J.; Misurcova, L.; Ambrozova, J.V.; Vicha, R.; Mlcek, J. Fatty acids composition of vegetable oils and its contribution to dietary energy intake and dependence of cardiovascular mortality on dietary intake of fatty acids. Int. J. Mol. Sci. 2015, 16, 12871-12890. [CrossRef] [PubMed]

30. Bayrak, A.; Kiralan, M.; Ipek, A.; Arslan, N.; Cosge, B.; Khawar, K.M. Fatty acid compositions of linseed (Linum usitatissimum L.) genotypes of different origin cultivated in Turkey. Biotechnol. Biotechnol. Equip. 2010, 24, 1836-1842. [CrossRef]

31. Chen, H.; He, Q. Value-added bioconversion of biomass by solid-state fermentation. J. Chem. Technol. Biotechnol. 2012. [CrossRef]

32. Kumar, S.S.; Gupta, R. An extracellular lipase from Trichosporon asahii MSR 54: Medium optimization and enantioselective deacetylation of phenyl ethyl acetate. Process Biochem. 2008, 43, 1054-1060. [CrossRef]

33. Jadhav, D.D.; Patil, H.S.; Chaya, P.S.; Thulasiram, H.V. Fungal mediated kinetic resolution of racemic acetates to $(R)$-alcohols using Fusarium proliferatum. Tetrahedron Lett. 2016, 57, 4563-4567. [CrossRef]

34. Solarte, C.; Yara-Varón, E.; Eras, J.; Torres, M.; Balcells, M.; Canela-Garayoa, R. Lipase activity and enantioselectivity of whole cells from a wild-type Aspergillius flavus strain. J. Mol. Catal. B Enzym. 2014, 100, 78-83. [CrossRef]

35. Fan, Y.; Xie, Z.; Zhang, H.; Qian, J. Kinetic resolution of both 1-phenylethanol enantiomers produced by hydrolysis of 1-phenylethyl acetate with Candida antarctica lipase B in different solvent systems. Kinet. Catal. 2011, 52, 686-690. [CrossRef]

36. Liang, J.; Zhang, Y.; Sun, A.; Deng, D.; Hu, Y. Enantioselective resolution of ( \pm )-1-phenylethanol and ( \pm )-1-phenylethyl acetate by a novel esterase from Bacillus sp. SCSIO 15121. Appl. Biochem. Biotechnol. 2016, 178, 558-575. [CrossRef] [PubMed]

37. Vandenberghe, A.; Markó, I.E.; Lucaccioni, F.; Lutts, S. Enantioselective hydrolysis of racemic 1-phenylethyl acetate by an enzymatic system from fresh vegetables. Ind. Crops Prod. 2013, 42, 380-385. [CrossRef] 
38. Deng, D.; Zhang, Y.; Sun, A.; Hu, Y. Enantio-selective preparation of (S)-1-phenylethanol by a novel marine GDSL lipase MT6 with reverse stereo-selectivity. Chin. J. Catal. 2016, 37, 1966-1974. [CrossRef]

39. Boratyński, F.; Smuga, M.; Wawrzeńczyk, C. Lactones 42. Stereoselective enzymatic/microbial synthesis of optically active isomers of whisky lactone. Food Chem. 2013, 141, 419-427. [CrossRef] [PubMed]

40. Boratyński, F.; Dancewicz, K.; Paprocka, M.; Gabrys̈, B.; Wawrzeńczyk, C. Chemo-enzymatic synthesis of optically active $\gamma$ - and $\delta$-decalactones and their effect on aphid probing, feeding and settling behavior. PLoS ONE 2016, 11, e0146160. [CrossRef] [PubMed]

41. Boratyński, F.; Pannek, J.; Walczak, P.; Janik-Polanowicz, A.; Huszcza, E.; Szczepańska, E.; Martinez-Rojas, E.; Olejniczak, T. Microbial alcohol dehydrogenase screening for enantiopure lactone synthesis: Down-stream process from microtiter plate to bench bioreactor. Process Biochem. 2014, 49. [CrossRef]

42. Walczak, P.; Pannek, J.; Boratyński, F.; Janik-Polanowicz, A.; Olejniczak, T. Synthesis and fungistatic activity of bicyclic lactones and lactams against Botrytis cinerea, Penicillium citrinum, and Aspergillus glaucus. J. Agric. Food Chem. 2014, 62, 8571-8578. [CrossRef] [PubMed]

(c) 2018 by the authors. Licensee MDPI, Basel, Switzerland. This article is an open access article distributed under the terms and conditions of the Creative Commons Attribution (CC BY) license (http:/ / creativecommons.org/licenses/by/4.0/). 